\title{
Static dissolution experiments under hyperalkaline conditions with dispersed and confined SM539 glass
}

\author{
Karine Ferrand $^{1}\left[\right.$ (D) Sébastien Caes $^{1} \cdot$ Karel Lemmens $^{1} \cdot$ Sanheng Liu $^{1} \cdot$ Katrien Meert $^{2}$
}

Received: 19 November 2021 / Accepted: 20 January 2022 / Published online: 7 February 2022

(c) The Author(s) 2022

\begin{abstract}
In the context of the geological disposal of vitrified radioactive waste, cracks are expected at the full scale of the glass blocks. To simulate glass alteration in cracks, static dissolution experiments were conducted with confined SM539 glass powder, at $30{ }^{\circ} \mathrm{C}$ in a synthetic young cementitious water. Short and long-term glass dissolution rates were determined and compared with those measured in similar experiments with dispersed glass powder. A long-term rate $\sim 10$ times lower was found, which might be due to a limited access of the solution to the glass surface area, resulting in a much higher local SA/V and faster increase of local concentrations of leached glass constituents, with possibly a lower local $\mathrm{pH}$. In both types of experiments, the altered glass powder was characterised by XRD and SEM-EDX. Some glass particles showed the presence of an amorphous multi-layer and of fibrous and spherical secondary phases.
\end{abstract}

\section{Introduction}

At the international level, deep geological disposal is the reference solution for the long-term management of high-level and/or long lived radioactive waste, including the vitrified waste coming from reprocessing of spent nuclear fuel [1, 2]. Such a geological disposal relies on a combination of engineered barriers and a natural barrier to avoid the release of radionuclides and other contaminants above concentrations at which they could present an unacceptable risk for man and the environment. The engineered barriers should be designed to provide complete containment of the heatgenerating waste at least during the thermal phase. Concrete is one of the engineered barrier materials. Hence, after a certain time, the glass will be exposed to (hyper)alkaline cementitious water. A research programme was developed at SCK CEN to determine glass dissolution rates and alteration mechanisms under such conditions [3, 4]. Most of the experiments were static glass dissolution experiments, i.e. without leaching solution renewal, which were conducted to study the dissolution rate in closed systems, where the

Karine Ferrand

karine.ferrand@sckcen.be

1 R\&D Waste Packages, Institute for Environment, Health and Safety, Belgian Nuclear Research Centre, Boeretang 200, 2400 Mol, Belgium

2 ONDRAF/NIRAS, Kunstlaan 14, 1210 Brussel, Belgium cement water composition evolves as a consequence of the glass dissolution. The temperature of $30{ }^{\circ} \mathrm{C}$ was selected as a reference temperature, as it is not too far from the expected host rock temperature in the Belgian disposal system $\left(16^{\circ} \mathrm{C}\right)$. As part of this programme, static dissolution experiments were carried out to investigate whether glass alteration is different for the internal surface (the cracks) and the external surface of the glass. Indeed, the $\mathrm{pH}$ in the cracks might be not as high as the $\mathrm{pH}$ of the cement pore water and, as the dissolution will progress, cracks could be filled with precipitates, leading to a decrease of the glass dissolution rate. This paper presents a summary of these static dissolution experiments performed at $30{ }^{\circ} \mathrm{C}$ in a synthetic young cementitious water with both confined and dispersed SM539 glass powder. SM539 is a Belgian reference waste glass.

\section{Materials and methods}

SM539 glass monoliths and glass powder with a 53-125 $\mu \mathrm{m}$ size fraction and a BET $(\mathrm{Kr})$ specific surface area of $0.120 \pm 0.001 \mathrm{~m}^{2} / \mathrm{g}$ were prepared as described in the supporting information (S.I). The nominal composition of SM539 glass is given in Table S1. The leaching solution was a synthetic young cementitious water (YCWCa) with a $\mathrm{pH}_{\left(30{ }^{\circ} \mathrm{C}\right)}$ of $13.3 \pm 0.2$, containing $12,900 \pm 1200 \mathrm{mg} / \mathrm{L}$ of $\mathrm{K}, 3300 \pm 320 \mathrm{mg} / \mathrm{L}$ of $\mathrm{Na}$, and $16 \pm 1.5 \mathrm{mg} / \mathrm{L}$ of $\mathrm{Ca}$. Static dissolution experiments with glass powder were conducted 
with slow magnetic stirring (130 rotations per minute using a magnetic stirrer with $9.5 \mathrm{~mm}$ diameter and $38 \mathrm{~mm}$ length) in an oven at $30{ }^{\circ} \mathrm{C}$ placed in a glove box under Ar atmosphere. In one test series, the glass powder was tightly confined between a wire mesh. In this setup, the cracks were simulated by the narrow interstitial space between the glass particles. In another test series, the glass powder was dispersed. For all experiments, $3.5 \mathrm{~g}$ of glass powder and four glass monoliths were added in $130 \mathrm{~mL}$ of YCWCa, corresponding to a glass powder surface area to solution volume ratio (SA/V) of $3230 \mathrm{~m}^{-1}$ (Fig. 1 and Table S2). In experiments with confined glass, the local SA/V ratio (considering only the volume inside the wire mesh) was, however, much higher, i.e. $200,000 \mathrm{~m}^{-1}$. Both types of experiments were performed in duplicate. A blank test without glass was also conducted, showing that the solution composition was constant over time. The sampling procedure is given in the S.I. From the elemental concentrations released in the bulk solution, the normalised losses (NL) and the retention factors were calculated (SI Eqs. 1-2). The (possibly different) concentrations between the confined glass particles could not be measured. Under the experimental conditions used in this study, boron was considered as a good glass dissolution tracer allowing the determination of the equivalent glass alteration layer thickness and of the short- and long-term glass dissolution rates (SI Eqs. 3-4). For comparison, dissolution rates were estimated from the mass losses of the altered glass monoliths. At the end of the tests, i.e. after 313 days, the altered glass powder was characterised by $\mathrm{X}$-ray diffraction (XRD) and scanning electron microscopy with energy dispersive X-ray (SEM-EDX), as described in the S.I.

\section{Results and discussion}

During the whole test duration, the $\mathrm{pH}$ remained constant at the reference $\mathrm{pH}$ value of YWCa (Fig. S1). The elemental release of $\mathrm{Si}, \mathrm{B}, \mathrm{Ca}$ and $\mathrm{Al}$ with time is shown in Fig. 2.
In the experiments with dispersed glass, B concentration increased up to $\sim 825 \mathrm{mg} / \mathrm{L}$ after 313 days whereas it levelled off rapidly at $\sim 275 \mathrm{mg} / \mathrm{L}$ with confined glass. In both types of experiments, a similar evolution was observed for $\mathrm{Si}$ and $\mathrm{Al}$ concentrations: they increased and then levelled off at $~ 300-400 \mathrm{mg} / \mathrm{L}$ and $\sim 200-250 \mathrm{mg} / \mathrm{L}$, respectively. This might indicate that similar phases controlled Si and $\mathrm{Al}$ in solution, as suggested by SEM-EDX analysis. The $\mathrm{Ca}$ concentration decreased from 16 to $<3 \mathrm{mg} / \mathrm{L}$, which could be explained by the retention of $\mathrm{Ca}$ in the glass alteration layer made of an amorphous alteration layer and secondary phases, as shown by SEM.

The normalised loss (NL) for $\mathrm{Si}, \mathrm{B}, \mathrm{Al}$ and $\mathrm{Li}$ is given in Fig. 3. In all experiments, B and Li were released congruently in solution, whereas $\mathrm{Si}$ and $\mathrm{Al}$ were retained in the glass alteration layer, with a retention factor of $\sim 45 \%$ and $79 \%$ with confined and dispersed glass, respectively. NL(B) increased up to $\sim 2.4 \mathrm{~g} / \mathrm{m}^{2}$ after 313 days with dispersed glass whereas it levelled off at $\sim 1.1 \mathrm{~g} / \mathrm{m}^{2}$ after 203 days with confined glass. From the slopes of the NL(B) linear regressions, short-term dissolution rates of $0.07 \mathrm{~g} / \mathrm{m}^{2}$ day and $0.035 \mathrm{~g} / \mathrm{m}^{2}$ day were determined between 0 and 7 days with dispersed and confined glass, respectively. The long-term dissolution rate between 41 and 313 days with dispersed glass was equal to $0.0054 \mathrm{~g} /$ $\mathrm{m}^{2}$ day, which was 10 times higher than the long-term dissolution rate of $0.0005 \mathrm{~g} / \mathrm{m}^{2}$ day between 203 and 313 days with confined glass. The lower glass dissolution rate with confined glass is presumably caused by the reduced accessibility of the solution to the glass surface, resulting in a much higher local SA/V and faster increase of local concentrations of leached glass constituents, with possibly a lower local $\mathrm{pH}$. The glass dissolution rates reported in this study for the experiments with confined glass are lower than the maximum dissolution rate of $0.4 \mathrm{~g} / \mathrm{m}^{2}$ day measured in dynamic tests with YCWCa (unpublished data), i.e. 11 and 800 times lower for the short-term and long-term dissolution rates, respectively. From NL(B) after 313 days, equivalent glass alteration layer thicknesses of $\sim 0.5 \mu \mathrm{m}$

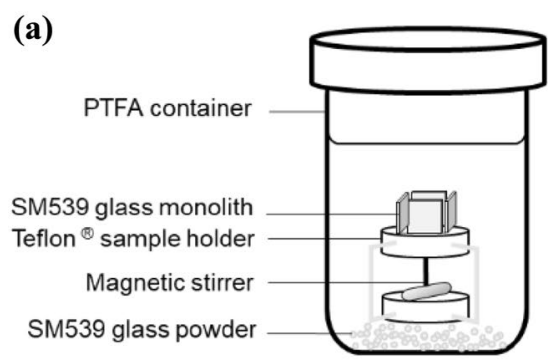

Fig. 1 a Experimental setup for the static dissolution experiments at $30{ }^{\circ} \mathrm{C}$ in YCWCa with dispersed SM539 glass; b sample holder attached to the lid of the container for the experiments with confined (b)

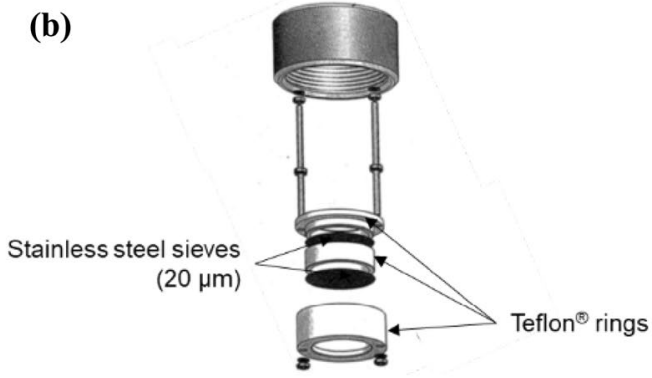

SM539 glass; after closure, it was immersed in the leaching solution above the sample holder in which glass coupons were mounted 

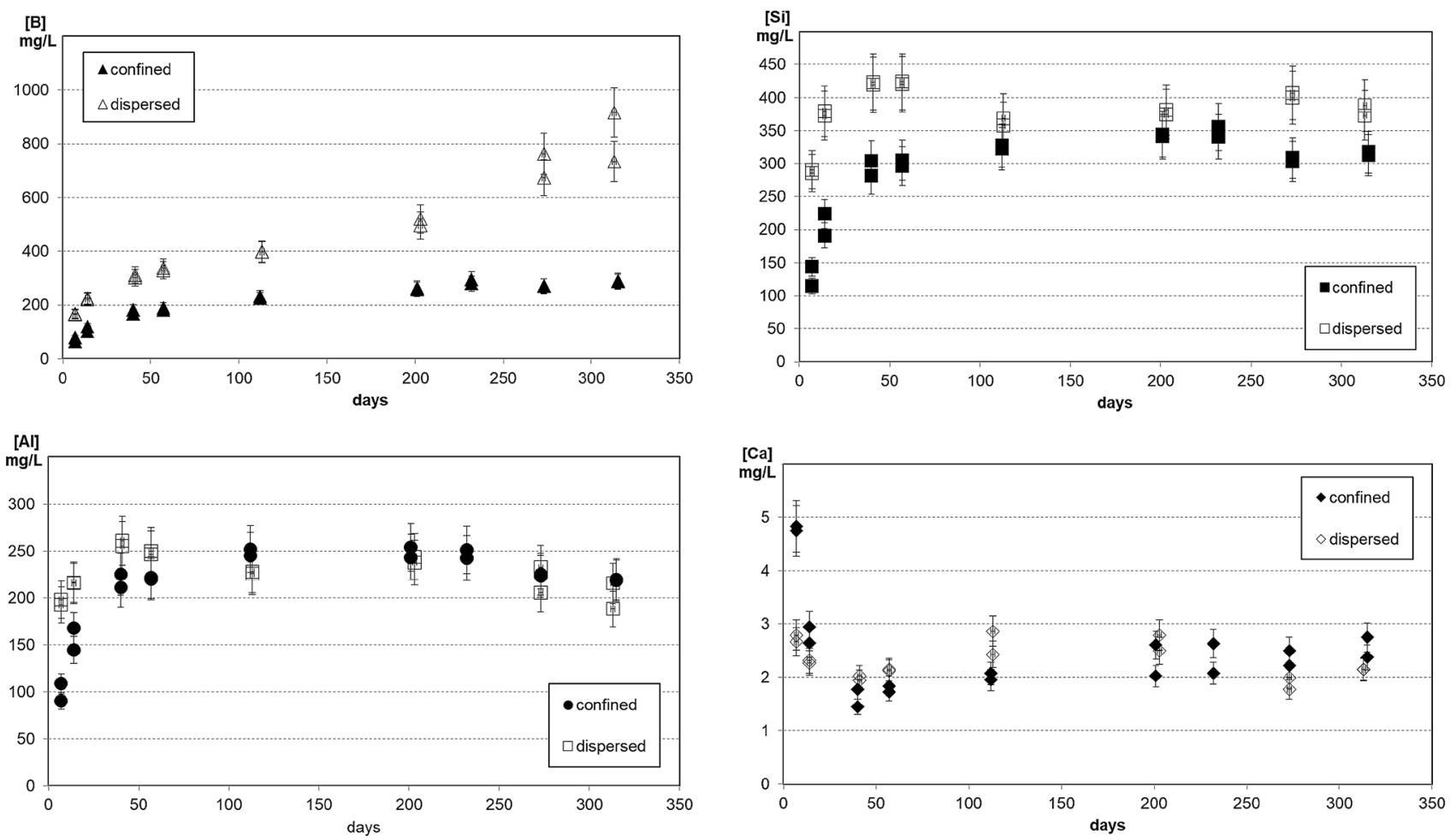

Fig. 2 Evolution of the boron, silicon, aluminium, and calcium concentrations in the static dissolution experiments at $30{ }^{\circ} \mathrm{C}$ in $\mathrm{YCWCa}$ with confined and dispersed SM539 glass powder
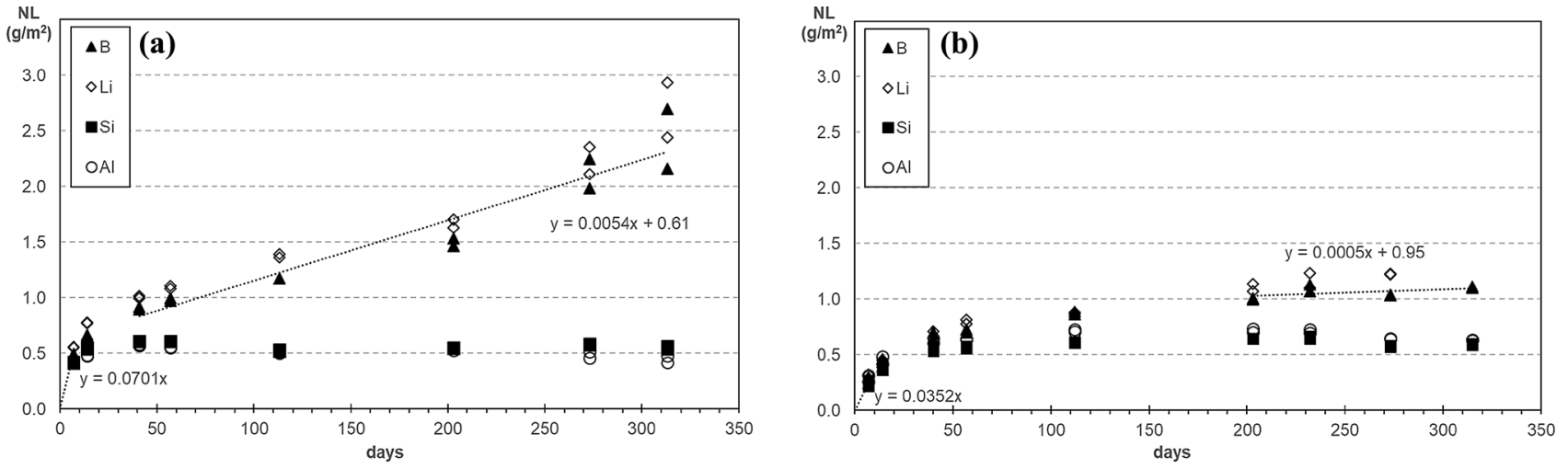

Fig. 3 Evolution of the boron, lithium, silicon and aluminium normalised losses in the static dissolution experiments at $30{ }^{\circ} \mathrm{C}$ in YCWCa with a dispersed SM539 glass and b confined SM539 glass

and $\sim 1.2 \mu \mathrm{m}$ were calculated with confined and dispersed glass.

In both types of experiments, glass dissolution rates from the monolith mass losses (Fig. S2) were comparable, as expected due to their similar position in the containers. They decreased with time from $\sim 0.12$ to $\sim 0.012 \mathrm{~g} / \mathrm{m}^{2}$ day, the latter rate being $\sim 2.2$ times higher than the long-term NL(B) rate with dispersed glass. Such a difference can be explained by an overestimation of the glass surface area by using BET measurement as reported in [5]. Consequently, the glass dissolution rates from the monolith mass losses are in agreement with those from NL(B) with dispersed glass.

XRD analysis on the glass powder altered for 313 days showed the presence of a broad peak between 15 and $40^{\circ}$ $(2 \theta)$ characteristic of amorphous silica from the unaltered glass (Fig. S3). A few diffraction peaks were detected, but the identification of the corresponding crystalline phases was not possible.

Regardless the type of experiments, after 313 days of leaching, the surface of the glass particles observed by SEM 
Fig. 4 SEM picture and elemental mappings of an altered glass particle showing lamellar layers and secondary phases
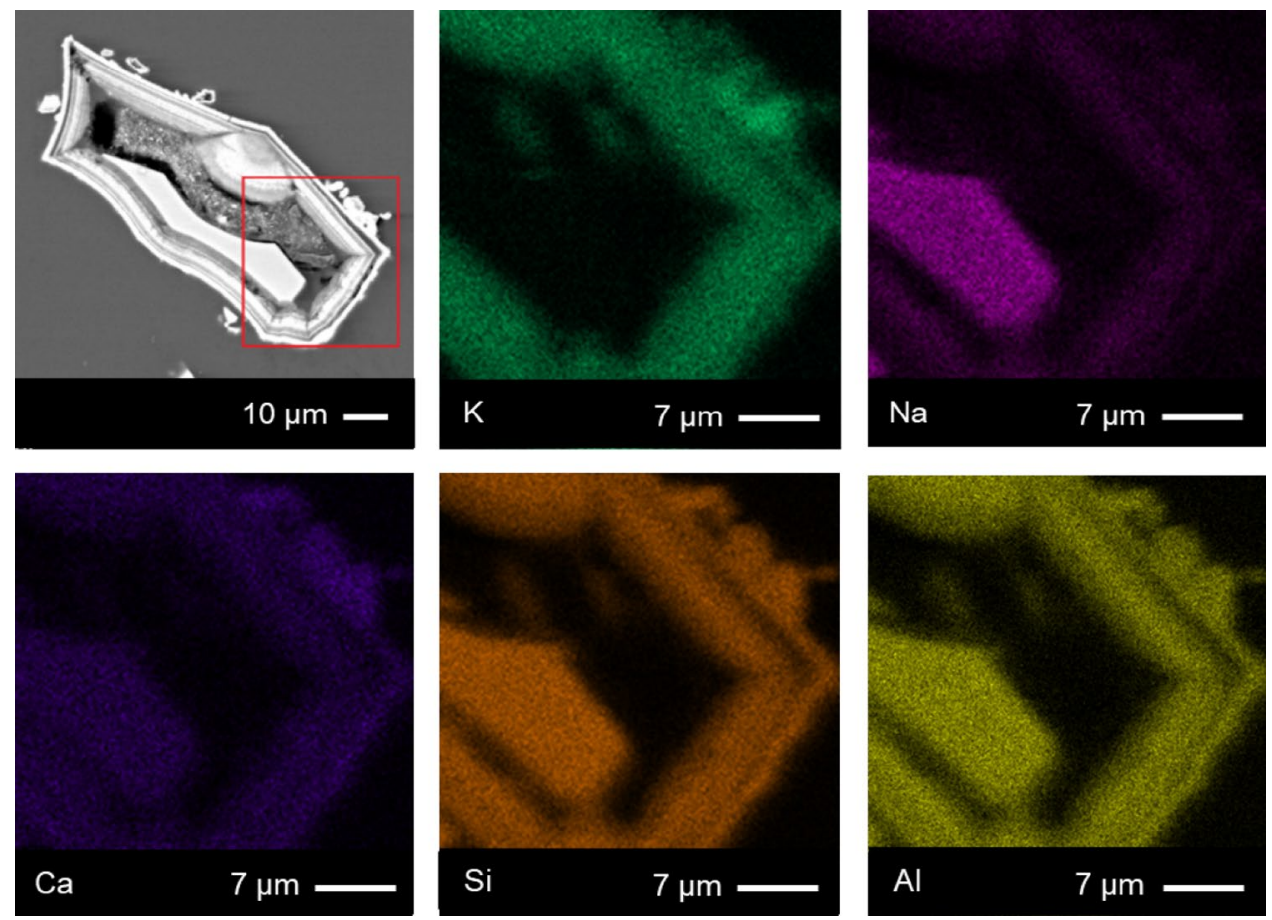

was not uniformly altered, and fibrous and spherical secondary phases were present (Fig. S4). The cross sections of some glass particles (Fig. 4) showed an amorphous alteration layer consisting of different regions: a dense band on the outer edge of the layer (i.e. in contact with solution), a finely banded region, where the bands were 'scalloped' in morphology, and a more porous region close to the surface of the unaltered glass. Both the amorphous layer and the secondary phases contained $\mathrm{O}, \mathrm{Si}, \mathrm{K}, \mathrm{Al}, \mathrm{Ca}$ and to a much lower extent $\mathrm{Na}$, with an $\mathrm{Al} / \mathrm{Si}$ ratio of 0.7 , and a $\mathrm{Ca} / \mathrm{Si}$ ratio of $\sim 0.2$, which is significantly lower than expected for Calcium Silicate Hydrates (typical end members have a $\mathrm{Ca} / \mathrm{Si}$ ratio of 0.8 and 1.6). Such glass alteration profiles with lamellar layers were reported by many authors [6-8] and can be explained by the dissolution/reprecipitation alteration glass model, as proposed in [9]. Based on the SEM pictures, the thickness of the amorphous alteration layer could reach up to $6 \mu \mathrm{m}$, which was much higher than the calculated thicknesses from NL(B).This indicates that some glass particles were altered with a rate of $0.05 \mathrm{~g} / \mathrm{m}^{2}$ day, which is close to the NL(B) short-term rate.

\section{Conclusions}

Static dissolution experiments were performed at $30{ }^{\circ} \mathrm{C}$ in a synthetic young cementitious water at $\mathrm{pH}_{\left(30^{\circ} \mathrm{C}\right)} 13.3$ with dispersed and confined SM539 glass powder. Based on the boron normalised losses, a long-term glass dissolution rate of $0.0054 \mathrm{~g} / \mathrm{m}^{2}$ day was determined with dispersed glass whereas a long-term rate $\sim 10$ times lower was measured with confined glass. This lower rate might be due to a limited access of the solution to the glass surface area, resulting in a much higher local $\mathrm{SA} / \mathrm{V}$ and faster increase of local concentrations of leached glass constituents, with possibly a lower local $\mathrm{pH}$. In future, the hypothesis of a possible $\mathrm{pH}$ decrease will be tested by performing geochemical calculations. In both types of experiments, SEMEDX analysis showed for some altered glass particles the presence of an amorphous multi-layer, which can be explained by the dissolution/reprecipitation glass alteration model. In addition, the presence of fibrous and spherical secondary phases growing on the amorphous layer was observed, but due to their very small amount, their identification was not possible. A grain size fractionation could be applied in order to separate the secondary phases from the altered glass particles, which might allow their identification by SEM-EDX and XRD. Other complementary techniques such as microfocused X-Ray Fluorescence and X-ray Absorption Spectroscopy could also be used for a better characterisation of the secondary phases. Moreover, the porosity of the amorphous multi-layer could be studied by Transmission Electron Microscopy.

Supplementary Information The online version contains supplementary material available at https://doi.org/10.1557/s43580-022-00214-5.

Acknowledgments This work was performed as part of the programme of the Belgian Agency for Radioactive Waste and Enriched Fissile Materials (ONDRAF/NIRAS) on the geological disposal of highlevel/long-lived radioactive waste. The authors are very grateful to 
Ben Gielen, Pieter Schroeders and Prisca Verheyen for the technical support.

Data availability All data presented herein are available upon request.

\section{Declarations}

Conflict of interest The authors have no relevant financial or non-financial interests to disclose.

Open Access This article is licensed under a Creative Commons Attribution 4.0 International License, which permits use, sharing, adaptation, distribution and reproduction in any medium or format, as long as you give appropriate credit to the original author(s) and the source, provide a link to the Creative Commons licence, and indicate if changes were made. The images or other third party material in this article are included in the article's Creative Commons licence, unless indicated otherwise in a credit line to the material. If material is not included in the article's Creative Commons licence and your intended use is not permitted by statutory regulation or exceeds the permitted use, you will need to obtain permission directly from the copyright holder. To view a copy of this licence, visit http://creativecommons.org/licenses/by/4.0/.

\section{References}

1. N. Chapman, A. Hooper, Proc. Geol. Assoc. (2012). https://doi. org/10.1016/j.pgeola.2011.10.001
2. ONDRAF/NIRAS Report - NIROND TR 2017-11 E V2 (2017)

3. K. Ferrand, M. Klinkenberg, S. Caes, J. Poonoosamy, W. Van Renterghem, J. Barthel, K. Lemmens, D. Bosbach, F. Brandt, Materials (2021). https://doi.org/10.3390/ma14051254

4. A. Elia, K. Ferrand, K. Lemmens, MRS Adv. (2017). https://doi. org/10.1557/adv.2016.672

5. M. Fournier, A. Nicoleau, Y. Inagaki, M. Odorico, P. Frugier, S. Gin, J. Nucl. Mater. (2016). https://doi.org/10.1016/j.jnucmat. 2016.04.028

6. C. Mann, K. Ferrand, S. Liu, J. Eskelsen, E. Pierce, K. Lemmens, C. Corkhill, N.P.J. Mater, NPJ. Mater. Degrad. (2019). https://doi. org/10.1038/s41529-018-0059-9

7. L. Dohmen, C. Lenting, R. Fonseca, T. Nagel, A. Heuser, T. Geisler, R. Denkler, Int. J. Appl. Glass Sci. (2013). https://doi. org/10.1111/ijag.12046

8. A. Verney-Carron, S. Gin, G. Libourel, J. Nucl. Mater. (2010). https://doi.org/10.1016/j.jnucmat.2010.09.028

9. T. Geisler, T. Nagel, M. Kilburn, A. Janssen, J. Icenhower, R. Fonseca, M. Grange, A. Nemchin, Geochim. Cosmochim. Acta (2015). https://doi.org/10.1016/j.gca.2015.02.039 